JULIA VLADIMIROVNA BALAKINA

National Research University Higher School of Economics, Nizhny Novgorod

julianaumova@gmail.com

ALEXEY VLADIMIROVICH SOSNIN

National Research University Higher School of Economics, Nizhny Novgorod

alexsosnin@mail.ru

\title{
INTERSEMIOTICITY AND MULTIMEDIA: TRANSITION FROM TRADITIONAL TO ELECTRONIC TEXTS
}

Keywords: intersemioticity, multimedia, intertextuality, electronic text, semiotics

\begin{abstract}
The article looks into such features of modern electronic texts as intersemioticity and multimedia nature. Studying these features is essentially a new stage in researching intertextual relations; hence the article first turns to non-electronic texts, presenting on their basis the theoretical grounds of the notions in question, and only then proceeds to electronic texts tracing the evolution of the traditional conception of text. Electronic texts are regarded as multimodal, i.e. resulting from the synthesis of diverse semiotic objects and joining text and media in one syntagm. In order to distinguish the most common combinations of text and media, to explore the reasons why users combine them, and to establish their percentage ratios, the authors have conducted a social and linguistic study, whose results are analyzed in the article.
\end{abstract}

\section{Introduction}

In a globalized world, the electronic means of communication are swiftly gaining popularity with people of all ages and nationalities, superseding the traditional means of information exchange. This process has already been given thorough consideration in a number of linguistic studies dedicated to the analysis and comparison of the two communication forms (Herring 2001; Thurlow 2004; Ess 2005; Balakina 2011, 2016; Crystal 2011; Chesnokova 2011; Zavyalova 2014). Virtually all of them point out that a basic feature of electronic texts is their multimedia nature, 
i.e. unlike the traditional monomedia texts, they are essentially symbiosis of text proper and media objects (audio and video components). Building up on the recent research, the present article seeks to expound the concepts of textual multimedia and intersemioticity at the stage of transition from traditional texts to electronic communication. Within this general aim, we shall turn to non-electronic texts at first, setting out the general theoretical prerequisites on their basis, and then proceed to electronic or virtual texts. Furthermore, from the results of a sociological survey conducted, we shall present the logic behind users' resorting to multimedia in the modern communication vehicles.

\section{Prerequisites to studying multimedia}

The concept of multimedia is close to that of intersemioticity or, according to the contemporary Russian semiotician Andrey Bochkaryov (2003: 62), the dynamic interaction of polytypic or heterogeneous semiotic systems. Indeed, the text as such is not the result of linguistic activity exclusively - it is subject to study from the perspective of multitudinous codes responsible for its formation, for shaping it into a whole. Intersemioticity is thus understood in terms of interplay between diverse semiotic modes, their relations and contribution to the meaning-making process (cf. Heibach 2003). For instance, instead of linguistic signs constituting the textual sequence, the language of visual arts uses visual or iconic signs. It should be noted, however, that verbal messages are of linear nature, whereas visual communication is two-dimensional rather than that, as the recipient who is looking at an image perceives its message holistically (cf. Martinet 1960: 380).

An exploration into intersemioticity and multimedia marks a new stage in studying intertextuality or, according to Kristeva (1986: 39), the continuous dialogue between texts that collectively constitute the global intertext of the cultural tradition. It is noteworthy that she also perceives intertextuality as the transposition of one or several sign-systems into another (Kristeva 1986: 111).

Viewed as recurrence or reproducibility, intertextuality refers to the relationship between the given text and other texts, which recur in it and can be either fictional or non-fictional; it is textual interaction in the planes of expression and content.

Intertextuality is a concept reverse to that of textual self-sufficiency. A self-sufficient text or a text per se can be characterized as a sign sequence which is internally organized, complete and autonomous in its content and structure. The meaning of this sequence is drawn from the semantics of the signs and the links between them. A self-sufficient text is a close system - no additional meaning-making entity is necessary to comprehend it. By this entity we understand a precedent text or a superstructure like a pratext or prototext lying in the basis.

A multimedia text will not be self-sufficient by default, as it will contain additional non-verbal semiotic objects adding to or modifying its general linguistic meaning.

Objects belonging to other than linguistic semiotics can be verbally or descriptively introduced into traditional texts as well. ${ }^{1}$ At the same time, being familiar 
with, say, a visual intext can either help the reader to better understand the text or even be the necessary condition of its proper understanding. As Claude LéviStrauss (1983: 22), a researcher into the semiotics of art, put it, the conventional iconic signs in literature permit conveying all the diversity of sensual experience up to its subtlest nuances. This statement is quite in line with the idea expressed by Paul Ricoeur, a leading representative of philosophical hermeneutics. According to Ricoeur (1975: 245), iconicity includes the verbal aspect.

To illustrate how visual images can verbally be introduced into a written text, we shall quote an extract from the novel Nice Work by a contemporary British writer David Lodge. He describes the protagonist's office (she is a college professor) in the following manner: "The walls are covered with posters illustrative of various radical causes - nuclear disarmament, women's liberation, the protection of whales and a large reproduction of Dante Gabriel Rossetti's painting, The Lady of Shalott, which might seem incongruous unless you have heard Robyn expound its iconic significance as a matrix of male stereotypes of the feminine" (Lodge 1989: 67).

A non-English reader might not be so familiar with the Pre-Raphaelite artistic movement and its founder Rossetti to immediately visualize Lady Shalott's image from the eponymous ballad by Alfred Tennyson. On the contrary, an English reader, even disinclined to read the novel from the gender perspective, knows the image very well. The Lady of Shalott is a canonical text and was the most illustrated ballad in England in the $19^{\text {th }}$ century.

In such cases we can state that the text transcends the borders of the linguistic dimension and turns multidimensional.

Thus, intersemioticity consists in the interaction of various sign types, e.g. of linguistic phonetic signs and graphic means - as in the so-called graphic rhyme in English poetry. Given below is an excerpt from the elegiac poem In Memoriam A.H.H. by a Victorian poet Alfred Tennyson: "O yet we trust that somehow good / Will be the final goal of ill, / To pangs of nature, sins of will, / Defects of doubt, and taints of blood" (Tennyson 1994: 313) (italics added). Here "good" [gud] rhymes with "blood" [blıd] - visually and not phonetically, i.e. a visual graphic "consonance" substitutes an auditory one. It is not fortuitous that we should have chosen a mid-1 $19^{\text {th }}$ century poem - the graphic rhyme cannot be explained in it by stylization or a purposeful return to the archaic norm (as the case is in Walter Scott's ballads, for example). According to Victor Zhirmunsky, a Russian literary historian, a rhyme for the eye would mean the satisfaction that the reader would derive from a symmetrical arrangement of typographic symbols, but in this sense, it is as impossible as a paper

\footnotetext{
It is traditionally acknowledged that each text carries both intratextual and extratextual information. Academician Andrey Kolmogorov, a major mathematician of the $2 \mathrm{O}^{\text {th }}$ century, ventured a similar idea that the full entropy of speech (i.e. the measure of information it conveys) can be resolved into (i) speech information proper and (ii) out-of-speech information (Kolmogorov 2003: 143-144). From the semantic standpoint, each textual component $t_{n}$ can be represented as the sum of the intratextual information seme $\mathrm{v}_{\mathrm{n}}$ and a large number of extratextual information semes $\mathrm{z}_{\mathrm{ni}}$ (e.g. socially-normative and idiolectal semes, extratextual linguistic semes referring the reader to other written texts, extratextual visual or auditory semes, etc.) (Sosnin 2012: 197).
} 
accord (Zhirmunsky 1923: 108). The graphic rhyme is accounted for by a lengthy and conservative poetic tradition and expresses (sic!) the pronouncing potential of the English language.

Another manifestation of intersemioticity is the interdependence of the immediate textual meaning and the graphic form of the text (letter size, font, capitalization, etc.). A classic example of this cited by Bochkaryov (2003: 93) is the graphic representation of text in visual poetry, whose apologists sought to turn typographic symbols into figurative images and independent iconic signs. We can also mention here the experiments with text and graphics done by vorticists, representatives of the English avant-garde, and published in Blast magazine. A representative of the movement, sculptor Henry Gaudier-Brzeska declares in a vorticist manifest, "I SHALL DERIVE MY EMOTIONS SOLELY FROM THE ARRANGEMENT OF SURFACES, I shall present my emotions by the ARRANGEMENT OF MY SURFACES, THE PLANES AND LINES BY WHICH THEY ARE DEFINED" (GaudierBrzeska 1915: 34). This is probably the minimum vorticists did in their text and graphics experiments.

Play with font and orthography is fairly widespread in modern electronic discourse too. It is by no means uniform and has certain varieties:

- the use of special symbols in spelling words, especially usernames or nicks, in order to imitate their traditional graphic form and to appear original at the same time: “@1ex" instead of "Alex";

- intentionally incorrect spelling (the errative) to create a comic effect, as in the following (though traditional) example: “There was a composer named Liszt / Whose music no one could resiszt. / When he swept the keyboard / No one could be bored; / And now that he's gone he is miszt";

- the same to cause the effect of singularity or eccentricity, to break the conservative norm (which might be regarded as a mechanism of oppressing people by the establishment), or for greater visual gratification, as the recent obsession with the letter " $k$ " in the USA: "I kan" for "I can"; captions to the so-called lolcats (macro-images of cats on the Internet): "I is cryin cuz $i$ is outa fokuss" (this one combines the wrong grammar, the "traditionally" wrong spelling and the "innovatively" wrong spelling);

- simplified spelling, abbreviation, substitution of figures for letter combinations to save time and space when texting or communicating in messengers: "My summr hols wr CWOT. B4, we used 2 go2 NY $2 \mathrm{C}$ my bro. ILNY its a gr8 plc", which stands for "My summer holidays were a complete waste of time. Before, we used to go to New York to see my brother. I love New York. It's a great place".

The presence of polytypical semiotic systems and/or multimedia is not an inherent feature of all communication vehicles, and it chiefly depends on the author's preferences and the communicative situation. At present however, a number of linguists point out the prevalence of the visual component over text in electronic discourse (Crystal 2011; Locher 2014), which they regard as a natural process related to the economy of time and effort. 


\section{Electronic texts}

Before turning to the analysis of electronic discourse multimedia content, we shall consider the general concept and peculiarities of electronic texts.

An electronic text (ET) is a text produced with the help of an information carrier (personal computer, laptop, tablet, mobile or smartphone) and combining to a certain extent the features of both spoken and written speech (Balakina 2016: 30).

There exist a number of criteria to classify electronic texts, among them:

- the means of communication used to create the text;

- source;

- intertextual relations;

- multimedia potential;

- completeness / possibility of editing;

- form and structure;

- the superimposition of spoken and written speech features, etc.

Let us note, however, that the number of ET types is significant, and a great many of them are quite similar or interrelated, which partly impedes their classification. At the same time, each group of closely related ETs has its own unique features depending on the information transfer channel, their traditional text counterparts or the context.

Some electronic texts coincide with traditional ones in their basic features, but each time they acquire a new peculiarity distinguishing them from traditional texts (hyperlinks, multimedia, possibilities of editing, etc.), the gap between them becomes all the more obvious.

We have chosen two groups of ETs to collect material for the socio-linguistic research reported on in the article:

- messages created with the help of the mobile phone in cross-platform applications like "Viber", "WhatsApp", and "Skype";

- messages in social networks, which are accessible both from the mobile phone and other means of communication (personal computer, laptop, tablet).

The basic reasons for choosing these ET types lie in their popularity and accessibility (the electronic networks can be accessed from several devices), as well as in their interface, which allows for combining text and media files.

\section{Media objects in electronic texts}

By analogy with ETs, media objects used in them fall into several categories:

1. Template objects: the media files furnished with the software. As a rule, every programme or web page has a set of visual objects, both static and dynamic. First of all, emoticons (or smileys, in simpler words) belong here, as well as other pictures, which the user just chooses from the set and inserts into electronic conversation. 
2. Copy-paste objects: pictures, photos, audio and video files that the user copies from other Internet resources and pastes into the conversation.

3. User objects: graphics, photos, audio and video created by users themselves. User objects can further be subdivided into synchronous, when, for instance, photos or video reports are being taken/shot during the communicative process, and asynchronous, in which case the media object was created and saved some time before the communication started. In the communicative act itself, the user just inserts it into the dialogue.

\section{Relationship between multimedia objects and text}

In his fundamental study into the relations between the image and the text, Barthes (1997) distinguishes three possibilities of how the iconic and verbal semiotic systems can coexist:

1. The text supplements the image, commenting on it and being anchored to it (anchorage status combinations). The text is largely a superfluous or "parasitic" message, accompanying the image. Figuratively speaking, it is not the image that illustrates the text, it is the text that is parasitic on the image (Barthes 1997: 25).

2. The image supplements or illustrates the text (illustration status combinations). It is only due to the image that the text will be interpreted correctly or "realized" (Barthes 1997: 25).

3. The text and the image are equally important, the shift between them being made according to the relay principle (relay status combinations). They supplement each other, and both the words - verbal signs - and the visual components - iconic signs - constitute a single syntagm, and therefore the cohesion of the whole message is achieved at a higher intersemiotic level (Barthes 1997: 31).

Martinec and Salway point out the prevalence of equal status combinations in the electronic means of communication. They also subdivide these combinations into independent and complementary (Martinec, Salway 2005: 345).

In equal status combinations, the whole image or video is related to the text in its entirety. In case the image is only related to a part of the text, or the text to a part of the image, we can speak of a subordinate status combination (Martinec, Salway 2005: 349).

Apart from the status as such, the logical and semantic text-image relations are of particular interest. Basing their research on the types of logical and semantic ties described in Halliday's (2004) systemic functional grammar, Martinec and Salway distinguish elaboration, extension, and enhancement as the text-image relationship forms. They further subdivide elaboration into exposition and exemplification. The fundamental distinction between them lies in the different degree of their component generality (Martinec, Salway 2005: 352). In the case of exposition, the text and the image have the same generality level, whereas it is diverse with illustration, i.e. either the text or the image possesses a more general meaning. 
Extension is the type of text-image relationship, when either of them adds new (but logically ensuing from the existing) information to the overall meaning of the textual-visual sequence.

In the case of enhancement, the text defines the image (or vice versa) depending on the relevant circumstances of time, place, cause, consequence, or purpose (Martinec, Salway 2005: 353).

Barthes believes that the image meaning is always bound and depends on that of the text to a certain extent, as images themselves are too polysemous: "to arrive at a definite meaning, language must come to the rescue. Visual meaning is too indefinite; it is a floating chain of signifieds" (Barthes 1997: 28). However, the advent of new technologies and the spread of multimedia have called Barthes' stance in question. For instance, in the paper "Reading images", Kress and van Leeuwen take the view that language and visual communication can both be used to realize the "same" fundamental systems of meaning that constitute our cultures, though each does so by means of its own specific forms, differently and independently. The writing may carry one set of meanings and the images carry another (Kress, van Leeuwen 2006: 19).

In order to find out the degree of textual self-sufficiency in reference to multimedia in electronic communication, we have conducted a social and linguistic survey, in the course of which 200 respondents aged 17-20 were offered to fill in a questionnaire. The respondents are active computer users and students of the Law, Economics and IT-in-Business departments of the Higher School of Economics in the city of Nizhny Novgorod, Russia. We have additionally staged an online poll of "Facebook" social network dedicated users. The whole survey was based on the users' personal experience and particular cases of electronic communication in "WhatsApp" and "Viber" cross-platform applications and "Facebook" and "Vkontakte" networks.

A part of the questionnaire aimed at finding out the text-image interrelation offers the respondents to choose the statement which is the most suitable for them:

a. In most of my messages the text interprets the media file; without the text, the photo/video can be understood wrongly.

b. The text and the media-file are fully meaningful each in its own right (the image could exist without the text in my messages and the other way round).

c. The media-file supplements (or illustrates) the text.

The following results have been obtained:

$65.6 \%$ of the respondents believe that the media supplements the text (the illustration status), i.e. at first the text is typed in and then the illustrative picture or video-file is attached to it.

For $21 \%$ of the users, the text and media have an equal status, and only $13.4 \%$ mention the anchorage status, when the text serves to interpret the media.

The results are summarized in Table 1.

We can conclude that despite the enormous potential of multimedia in electronic communication and the seemingly greater appeal of media objects as compared with writing, the text rather than video or audio still conveys most of the meaning and realizes the communicative task. 


\begin{tabular}{|c|c|c|}
\hline $\begin{array}{ll}\text { Media Object Status } & \text { Sex } \\
\end{array}$ & $\mathbf{F}$ & $\mathbf{M}$ \\
\hline Illustration & $67.8 \%$ & $60 \%$ \\
\hline Equal & $17.7 \%$ & $30 \%$ \\
\hline Anchorage & $14.5 \%$ & $10 \%$ \\
\hline
\end{tabular}

Table 1. Interrelation of text and media objects in electronic messages

\begin{tabular}{|c|c|c|}
\hline Rationale Sex & $\mathbf{F}$ & $\mathbf{M}$ \\
\hline Economy of effort & $30.8 \%$ & $50 \%$ \\
\hline $\begin{array}{l}\text { Effect of personal presence, } \\
\text { face-to-face communication }\end{array}$ & $69.2 \%$ & $50 \%$ \\
\hline
\end{tabular}

Table 2. Preferences in using media objects in electronic messages

\section{Reasons for combining text and media}

As the survey results indicate, media objects most often serve as merely an illustration to the text. Nevertheless, the nearly unlimited possibilities of their application in electronic discourse allow them to harmoniously fit in the context and to even supplant text from communication in some cases without violating the author's general communicative intention.

Hence the question as to the reasons for combining text and media in electronic messages. On the one hand, the functional aspect should be considered. The image undoubtedly exerts greater emotional influence on an interlocutor than the text, which is more suitable for establishing logical links (cf. Arnheim 1989: 255). A simple fascination with reproducing the visual part of our experience may also lie behind this, the desire to achieve transparency, or "immediacy" in communication (cf. Bolter 2000: 65) - as if our interlocutor were looking with his/her own eyes at what is going on, and were providing real-time comments.

On the other hand, all the means of communication can be described from the economy-of-effort standpoint. It is apparently simpler to take and send a photo than to create a detailed description of the situation by typing in text.

To establish the prevailing reasons for combining text and media, the respondents were offered the following question: "In what cases do you prefer to use multimedia (photo or video) files instead of text in your messages?". The following possible answers were supplied: 
a. Economy of effort (it is easier and faster to insert a photo/video file than to type in text).

b. A photo/video file creates the effect of participation or real-time communication.

The results vary according to the respondents' sex. $30.8 \%$ of females use media-files to minimize effort and $69.2 \%$ to create the effect of face-to-face communication. At the same time, 50\% of males name the first reason and 50\% the second.

On the whole, both the reasons play nearly the same role in choosing between text and media, and testify to the unique nature of electronic communication.

\section{Frequency of media files in electronic communication}

Let us once again stress that the possibility of combining text proper with multimedia objects (pictures, photos, audio and video) is the substantial difference between electronic and traditional texts. After insertion in the text, these objects become its inherent components structurally and semantically. There appear the so-called combined or "multimodal texts", where the heterogeneous objects or "modes" are, on the one hand, relatively autonomous and can easily be singled out, but on the other hand, they are integrated in a unified syntactic and semantic structure (Martinec 2010: 339-340).

To find out how frequent multimodal texts are in everyday electronic communication, we invited the respondents to do the following:

1. Please have a look at your ten last messages in applications like "Viber" or "WhatsApp".
a. How many of the ten messages consist of text only?
b. How many of the ten messages consist of photos/video only?
c. How many of the ten messages consist of text and photos/video?

2. Please have a look at your ten last messages in social networks like "Facebook" or "Vkontakte".

a. How many of the ten messages consist of text only?

b. How many of the ten messages consist of photos/video only?

c. How many of the ten messages consist of text and photos/video?

The respondents to the questionnaire have examined a total of 4,00o messages. The pie chart in Figure 1 summarizes the results of this fragment of our study.

More detailed results are presented in Table 3.

On the whole, it can be inferred that text-only messages still prevail over multimodal or multimedia messages with both males and females, which testifies to the pivotal role of the traditional text even in modern electronic communication. A half of the male respondents and one-third of the females choose to use visual objects in their messages, aiming to minimize their effort.

Hence, textual multimedia is a result of the interaction of diverse sign systems and it is a feature of electronic texts exclusively. Nevertheless, multimodal objects 


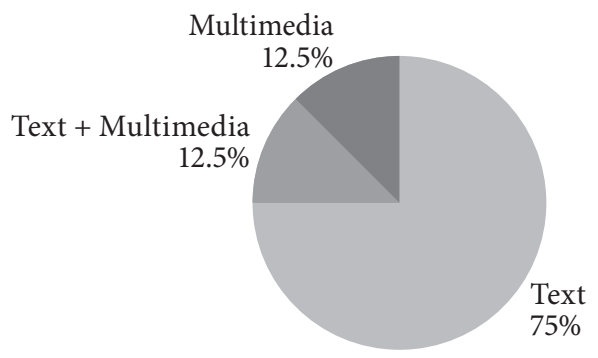

Figure 1. Text-media combinations in electronic messages

Females

\begin{tabular}{|c|c|c|c|}
\hline & $\begin{array}{l}\text { Cross-platform } \\
\text { applications }\end{array}$ & Social networks & $\begin{array}{l}\text { Cross-platform } \\
\text { applications }+ \\
\text { social networks }\end{array}$ \\
\hline Text only & $77.0 \%$ & $81.0 \%$ & $79.0 \%$ \\
\hline Media only & $12.5 \%$ & $9.9 \%$ & $11.1 \%$ \\
\hline Text + media & $10.5 \%$ & $9.1 \%$ & $9.9 \%$ \\
\hline \multicolumn{4}{|c|}{ Males } \\
\hline & $\begin{array}{l}\text { Cross-platform } \\
\text { applications }\end{array}$ & Social networks & $\begin{array}{l}\text { Cross-platform } \\
\text { applications }+ \\
\text { social networks }\end{array}$ \\
\hline Text only & $65.0 \%$ & $61.0 \%$ & $62.7 \%$ \\
\hline Media only & $18.9 \%$ & $16.3 \%$ & $17.4 \%$ \\
\hline Text + media & $16.1 \%$ & $22.7 \%$ & $19.9 \%$ \\
\hline
\end{tabular}

Table 3. Text-media balance in electronic messages

constituting these texts interact with each other on the basis of intersemiotic mechanisms, which can also be found in traditional printed or written texts.

The survey conducted has amply shown that despite the advance of electronic communication it is still early to postulate the prevalence of the visual content over textual. Still, multimedia in electronic communication boasts two unique features, which users willingly resort to and which could eventually supersede traditional texts. The participation effect and economy of effort are these features. However, they do not seem to be of primary importance at present. We should 
also like to emphasize that due to its structural peculiarities, each semiotic system imposes certain limitations on the set of meanings it can transmit. One cannot "read" in an image everything that language would convey. The opposite is also true, though.

It can be concluded that multimodality is not a totally new phenomenon, as it is based on the concept of intersemioticity, which, as the theoretical part of the article suggests, has been the subject of scientific research for a number of years. However, it is only with the advent and proliferation of electronic texts that these notions have acquired specific and even unique features. It is primarily related to the fact that the modern forms of communication permit combining text with both static media-objects (e.g. photos) and dynamic ones (audio- or video-sequences). Hence the transformation of the very concepts of multimodality and intersemioticity.

Given the apparent advantages of media-objects over traditional texts, we could have expected the prevalence of the former in electronic communication. Nevertheless, our study has indicated that even the youngest and most enthusiastic users of electronic communication means are not ready to fully substitute media-objects for text messages. As the respondents belong to the so-called Internet generation, it will be fair to suggest that other age groups, who are less involved in electronic communication, would prefer the traditional printed text even to a greater degree. The human mind is not yet prepared to switch from text to visualization entirely, even though multimedia technologies have certainly reached an advanced level, being able to function independently and effectively. At the present stage, the mind still tends to clearly differentiate between diverse semiotic systems and the meanings which they are capable of conveying. Still, this situation is apparently subject to on-going change, hence the implications of the present research for a more detailed psycholinguistic study into the potential of human mind.

\section{Appendix}

\section{The Questionnaire}

1. Your sex

2. Your age

3. Please have a look at your ten last messages in applications like "Viber" or "WhatsApp".
a. How many of the ten messages consist of text only?
b. How many of the ten messages consist of photos/video only?
c. How many of the ten messages consist of text and photos/video?

4. Please have a look at your ten last messages in social networks like "Facebook" or "Vkontakte".
a. How many of the ten messages consist of text only?
b. How many of the ten messages consist of photos/video only?
c. How many of the ten messages consist of text and photos/video? 
5. In what cases do you prefer to use multimedia (photo or video) files instead of text in your messages?

a. Economy of effort (it is easier and faster to insert a photo or a video file than to type in text).

b. A photo/video file creates the effect of participation or real-time communication.

6. Which of the statements below looks most suitable for you?

a. In most of my messages the text interprets the media file; without the text, the photo/video can be understood wrongly.

b. The text and the media-file are fully meaningful each in its own right (the image could exist without the text in my messages and the other way round).

c. The media-file supplements (or illustrates) the text.

\section{References}

Arnheim R. 1989. The semiotic web. Berlin.

Balakina J. 2011. Anglicisms in Russian and German blogs. Frankfurt am Main.

Balakina J. 2016. Electronic texts - a cardinally new textual type? - Vestnik Volgogradskogo Gosudarstvennogo Universiteta 3: 29-35.

Barthes R. 1997. Image-Music-Text. London.

Bolter J. 2000. Remediation: Understanding new media. Cambridge.

Bochkaryov A. 2003. Intersemiotichnost'. Semanticheskij slovar'. [= The Dictionary of semantics]. Nizhny Novgorod.

Chesnokova I. 2011. Osobennosti ustnoj/pis'mennoj rechi v elektronnom pis'me. [= Oral and written features of electronic mail]. - Vestnik Burjatskogo gosuniversiteta 11: 132-135.

Crystal D. 2011. Internet linguistics: A student guide. London.

Ess Ch. 2005. Culture and computer-mediated communication: Toward new understandings. - Journal of Computer-Mediated Communication 11.1: 179-191.

Gaudier-Brzeska H. 1915. Vortex (written from the trenches). - Blast [War Number] 2: 33-34.

Heibach C. 2003. Literatur im elektronischen Raum. Frankfurt am Main.

Herring S. 2001. The handbook of discourse analysis. Oxford.

Kolmogorov A. 2003. The truth benefits. [vol. 1]. Moscow.

Kress G., van Leeuwen T. 2006. Reading images. [ $2^{\text {nd }}$ edition]. London.

Kristeva J. 1986. The Kristeva reader. Oxford.

Halliday M.A.K. 2004. An introduction to functional grammar. [ $3^{\text {rd }}$ edition; revised by M.I.M. Matthiessen]. London.

Lévi-Strauss C. 1983. The raw and the cooked. [Mythologiques, vol. 1]. Chicago.

Locher M.A. 2014. The pragmatics of discourse. Berlin.

Lodge D. 1989. Nice work. NY.

Martinet A. 1960. Elements de linguistique generale. Paris.

Martinec R., Salway A. 2005. A system for image-text relations in new (and old) media. Visual Communication 4: 339-374.

Ricœur P. 1975. La metaphore vive. Paris.

Sosnin A.V. 2012. Matematicheskoe obosnovanie mnogomernosti i nesamodostatochnosti teksta. [= Mathematical description of the multi-dimensional and non-self-sufficient text]. - Vestnik Voronezhskogo gosudarstvennogo universiteta. Serija: Lingvistika i mezhkul'turnaja kommunikacija 1: 94-199. 
Tennyson A. 1994. The selected poems. Hertfordshire.

Thurlow C. 2004. Computer-mediated communication. London.

Zavjalova Z.S. 2014. Kommunikativnye transformacii social'nyh media. [= Communicative transformations of social media]. - Izvestija Tomskogo politehnicheskogo universiteta. Social'no-gumanitarnye tehnologii 6: 88-93.

Zhirmunskij V.M. 1923. Rifma, eyo istorija i teorija. [=Rhyme, its history and theory]. [vol. 3]. Petrograd. 